\title{
Guernica de Picasso y la Escuela de Nueva York (1939-1947)
}

\author{
María Dolores JimÉnez-Blanco CARrillo DE Albornoz \\ Universidad Complutense de Madrid \\ dolores.jimenezblanco@ghis.ucm.es
}

Recepción: 16 de febrero de 2010 / Revisión: 1 de junio de 2010

Aceptación: 2 de junio de 2010 / Publicación: diciembre de 2010

\begin{abstract}
RESUMEN
Guernica, la pintura realizada por Picasso en 1937 para el Pabellón Republicano en la Exposición Internacional de Artes y Técnicas de París, tuvo un fuerte impacto en la Escuela de Nueva York. En mayo de 1939 fue presentada en la capital americana como un icono político en el marco de una campaña internacional de ayuda a los refugiados republicanos. En noviembre de 1939 reapareció como indiscutible obra maestra del arte moderno en el contexto de la gran exposición antológica dedicada a Picasso por el Museo de Arte Moderno de esta ciudad. Sumando ambos significados, Guernica supuso un estímulo crucial para los artistas del expresionismo abstracto que, en el contexto de la crisis moral producida por la Segunda Guerra Mundial, exploraban la posibilidad de hacer un arte que expresara la conexión del mundo interior del pintor con los problemas de su tiempo, afirmando el papel del artista, como individuo, en la sociedad.
\end{abstract}

Palabras clave: Expresionismo Abstracto, Barr, Exposición Internacional de Artes y Técnicas, Guernica, Museo de Arte Moderno, Nueva York, Pabellón de la República Española, Picasso.

\section{Picasso's Guernica and The New York School (1939-1947)}

\begin{abstract}
Guernica, Picasso's painting for the Spanish Republican Pavilion in the International Exposition of Arts and Techniques of Paris, 1937, had a strong impact on the New York School. In May 1939 it was first exhibited in this city as a political icon within a campaign to raise funds for the Spanish Republic refugees. In November 1939 it was exhibited again as an undisputed modern art masterpiece in the frame of a great retrospective exhibition on Picasso's oeuvre at the Museum of Modern Art. By adding up these two meanings, Guernica acted as an important stimulus for abstract expressionist artists, who were looking for an art that could express the connection between the inner self of the artist and the problems of his time, and confirmed the role of the artist, as an individual, in society.
\end{abstract}

Keywords: Abstract Expressionism, Barr, Guernica, International Exposition of Arts and Technoques, Museum of Modern Art, New York, Spanish Republican Pavilion, Picasso.

SUMARIO: 1. De Las Meninas a Guernica. La pintura española como estímulo. 2. 1937. Guernica en París: creación y primeras reacciones críticas. 3. 1939. Guernica en Nueva York: de icono político a obra maestra. 4. 1947. Guernica y el Expresionismo Abstracto. 5. Coda. Vuelta a Las Meninas. 6. Referencias bibliográficas.

\section{DE LAS meninas a gUERNica. LA Pintura ESPAÑola COMO ESTÍMULO}

Si tuviéramos que señalar dos obras singulares que capturaron la atención de los artistas americanos estas serían, probablemente, Las Meninas de Velázquez y 
Guernica de Picasso, dos de las pinturas más emblemáticas de la historia del arte español. La primera dio lugar a numerosas reinterpretaciones y estudios por parte de los más notables pintores americanos de la "Guilded Age", que la conocieron en viajes a Madrid o mediante reproducciones. Whistler, Eakins, Merrit Chase y Sargent ${ }^{1}$ encontraron en aquella pintura las cualidades que buscaban para definir su propio arte, que debía servir además como emblema de los atributos de la propia nación americana: independencia, audacia, libertad, fidelidad a la naturaleza ${ }^{2}$. La segunda, por su parte, desde su llegada a Nueva York en 1939, se había convertido en referencia ineludible para los jóvenes artistas que pondrían en pie la llamada Escuela de Nueva York a mediados del siglo XX. Así, puede decirse que estas dos pinturas españolas estimularon a la pintura americana en dos momentos clave de su historia: en primer lugar, el de su decidida entrada en la modernidad internacional en las décadas finales del siglo XIX, coincidiendo con la ascensión de la nación americana al status de potencia mundial. En segundo lugar, el de la consagración del expresionismo abstracto, que convirtió a la ciudad de Nueva York en máximo exponente de la modernidad artística en el contexto de la segunda postguerra mundial, en los inicios de la llamada Guerra Fría. Este segundo momento, el del Triunfo de la pintura americana $^{3}$, centrará nuestro presente estudio. Pero antes realizaremos una última referencia a Las Meninas que nos permita relacionar de nuevo al modelo del siglo XVII con el del siglo XX. Jonathan Brown, uno de los más eminentes especialistas americanos en el arte español del Siglo de Oro, ha señalado la cuestión de la relación entre la forma y el contenido de Las Meninas como una de las principales razones de su atractivo. Como veremos, este fue también el caso de Guernica. Algunas de sus palabras sobre Las Meninas podrían igualmente aplicarse al cuadro de Picasso:

Tal tensión entre forma y contenido justifica la irresistible fascinación que el cuadro ha ejercido sobre escritores de cualquier género. Críticos, eruditos, poetas, autores teatrales y filósofos, todos han intentado llegar a su esencia, buscando una explicación verdaderamente definitiva de su significado; y al final lo único que han comprobado es que la pintura ha sabido sortear cada una de las trampas intelectuales que se le tendían con todo cuidado [...]. Como acontece a toda gran obra de arte, el tiempo no desgasta a Las Meninas, sino que la enriquece, permaneciendo siempre llena de vitalidad. Por las mismas razones, cada generación debe aceptar el desafío de interpretarla dentro de ese proceso de revitalización perpetua ${ }^{4}$.

Las Meninas y Guernica compartían aspectos que contribuyeron poderosamente a su atractivo. En primer lugar, su gran tamaño, que las convertía en piezas capaces de imponer respeto por su propia presencia material; en segundo lugar, su conexión con momentos cruciales de la historia, que les otorga una especial relevancia épica. Pero, junto a las dos cualidades que acabamos de señalar, será la tercera, la tensión

1 Boone, 2003, pp. 80-123.

2 WeINBERG, 2003, pp. 259-307.

3 SANDLER, 1970.

${ }^{4}$ Brown, 1978, p. 67. 
entre forma y contenido señalada por Brown a propósito de $\operatorname{Las}_{\text {Meninas }}{ }^{5}$, la que más contribuyó a convertir a Guernica en piedra de toque entre artistas, críticos y conservadores de museos en el Nueva York del expresionismo abstracto, donde se debatían cuestiones como el compromiso social del artista o el peso ideológico y moral del arte. A estas cuestiones iban asociadas, además, otras como la carga simbólica de las formas artísticas o, la dicotomía abstracción-figuración en relación con la capacidad de transmitir contenidos. Cuestiones que, de un modo u otro, encontrarían respuestas en Guernica de Picasso que en 1939 parecería experimentar una significativa metamorfosis: la que parte de una imagen de propaganda política para llegar a una obra maestra universal. En efecto, Guernica consiguió muy pronto trascender las circunstancias concretas de su creación para convertirse en una obra de significado universal, y en este cambio de status desempeñaron un papel primordial las circunstancias que marcaron su recepción crítica en Nueva York. De este modo, si Guernica fertilizó el ambiente artístico neoyorquino, este también influyó decisivamente en la fortuna de aquel.

\section{1937. GUERNICA EN PARÍS: CREACIÓN Y PRIMERAS REACCIONES CRÍTICAS}

Guernica surgió de un encargo cursado por el gobierno de la República española a Pablo Picasso, reconocido ya como uno de los pintores modernos de mayor prestigio internacional que, precisamente por ello, había sido nombrado unos meses antes director del Museo del Prado. Este nombramiento puso al pintor, al menos nominalmente, a cargo del lugar más sagrado del arte español, en el que se encontraba el lienzo que su padre le había mostrado como la obra cumbre de la pintura universal: Las Meninas. En este contexto, no debe extrañar que Picasso pensase ya entonces que Guernica, "el último gran cuadro de historia"6, pudiera unirse en el futuro a las demás obras del Prado?.

Ya en el mes de enero de 1937, los representantes de la República obtuvieron el compromiso de Picasso de hacer una gran obra para el pabellón que debía representar a la España amenazada por el fascismo en la Gran Exposición Universal de Artes y Técnicas, que se celebraría ese mismo año en París. Sin embargo, el pintor no comenzó a trabajar hasta que un hecho histórico consiguió conmoverle: el bombardeo de la villa vasca de Guernica, el 26 de abril de 1937, por parte de la Legión Cóndor alemana que quedó registrado en feroces imágenes reproducidas por los diarios franceses. A partir de ese momento se inicia un frenético proceso de trabajo que puede seguirse documentalmente mediante las fotografías realizadas por Dora Maar $^{8}$, que ponen de manifiesto los sucesivos estadíos del trabajo en el gran lienzo de dimensiones murales, situado en el estudio de la rue des Grands Agustins de París.

\footnotetext{
5 Ibídem.

6 Calvo Serraller, 2006, pp. 27 y ss.

7 CHIPP, 1981, p. 96.

8 Estas fotografías fueron publicadas en LARREA, 1947.
} 
Pero también puede reconstruirse mediante todo un conjunto de piezas que Picasso realizó al mismo tiempo que el Guernica, erróneamente consideradas como obras preparatorias, que pueden describirse como parte de un inmenso retablo del que Guernica sería la tabla central ${ }^{9}$. Se trata de un conjunto de más de sesenta piezas entre dibujos y lienzos, que vienen a sumarse al enorme lienzo de Guernica, que constituye probablemente uno de los de mayor formato realizados en su tiempo. Este dato, unido al corto período de realización -Picasso entregó el lienzo a las autoridades republicanas en la primera quincena de junio de 1937-, sugiere un ritmo de trabajo febril, que permite imaginar al artista ejecutando su trabajo en un estado de gran agitación creativa, casi de trance. Se trata, en definitiva, de un conjunto de piezas de gran fuerza expresiva en el que Picasso no sólo registra una tragedia histórica, sino que también, y sobre todo, deja aflorar su estado de ánimo frente a esa tragedia. Lo hace utilizando un lenguaje artístico plenamente moderno, que sintetiza muchas de sus propuestas artísticas anteriores, desde el cubismo sintético hasta el surrealismo.

La tensión existente entre la forma, inequívocamente moderna, y el trágico contenido de la pieza centró la discusión crítica sobre la obra cuando fue presentada en París con motivo de la inauguración del Pabellón Republicano, que tuvo lugar unas semanas más tarde de la apertura oficial de la Feria, concretamente el 24 de mayo de 1937. Los críticos cercanos al marxismo repudiaron amargamente el cuadro. Anthony Blunt, entonces un joven de 29 años, publicó el 6 de agosto una crítica en The Spectator acusando a Picasso de haber realizado sólo una asociación libre de ideas que demostraba que no había entendido la significación política de la destrucción de la villa de Guernica ${ }^{10}$. Por su parte, el poeta Luis Aragon, redactor jefe de L'Humanité, criticaba a Picasso, sin nombrarlo, caracterizándolo como a uno de esos artistas que creaban imágenes para los ricos y poderosos en lugar de crear ilustraciones claras del horror de la guerra, como las que proponía el realismo socialista. Atacaban en Guernica, pues, lo que ellos consideraban un defecto de indefinición o, mejor, de falta de concreción en su sentido propagandista. Un rasgo que, posteriormente, serviría a este cuadro para alzarse sobre el resto de las obras concebidas con diáfano sentido de propaganda, presentes en aquel y en el resto de los pabellones de la Exposición Internacional, y le permitiría adquirir la dimensión de universalidad por la que hoy sigue siendo admirado. En el lado contrario a aquellas críticas, artistas como Amedée Ozenfant defendieron el lienzo diciendo que "nuestra época es grandiosa, dramática y peligrosa [...], y Picasso, al ser igual que sus circunstancias, hace un cuadro digno de ellas"11. Este argumento sobre la necesaria conexión entre el artista y las circunstancias de su época cobraría especial relevancia en el contexto del expresionismo abstracto.

9 RAMireZ, 1994, pp. 42-50.

10 SEMPRÚn, 2006, p. 21.

11 Reproducido en CHIPP, 1981, p. 90. 


\section{1939. GUERNICA EN NUEVA YORK: DE ICONO POLÍTICO A OBRA MAESTRA}

En mayo de 1939, el mural picassiano se expone por primera vez en la ciudad de Nueva York, en la Valentine Gallery, como un símbolo de la resistencia al fascismo. En noviembre del mismo año, Guernica vuelve a aparecer ante el público neoyorquino. Esta segunda vez forma parte de una importante retrospectiva dedicada a Picasso en el Museo de Arte Moderno, y en ese marco asume la categoría de pieza clave en el desarrollo histórico de la obra del pintor, considerado a su vez como el artista clave del siglo XX. El cambio producido en la apreciación crítica de la pintura, pues, se produce en el corto espacio de unos meses, los que transcurren entre mayo y noviembre de 1939.

No era un año cualquiera: los acontecimientos se suceden entonces a un ritmo vertiginoso, en el que lo artístico y lo político se entremezclan hasta resultar difícilmente separables. Después de los años de la Gran Depresión, en el ambiente artístico neoyorquino se abre un período esperanzador. En 1939, el Federal Art Project se reorganiza, dando lugar al WPA Art Program. Ese mismo año, y sumándose al ya existente Museum of Living Art, que presentó entre 1927 y 1943 la colección de A. E. Gallatin en unas salas cedidas por la Universidad de Nueva York, abren sus puertas otros dos museos dedicados al arte moderno: el Museum of Non Objective Painting, germen del posterior Solomon R. Guggenheim Museum y, más importante, el Museum of Modern Art. Este último, originalmente fundado en 1929, inaugura en mayo un nuevo y moderno edificio con la exposición titulada "Art in Our Time", y es saludado por el presidente Franklin D. Roosevelt como "una institución nacional (que) puede enriquecer y dar vigor a nuestra vida cultural acercando lo mejor del arte moderno al pueblo americano" 12 , pero también como un importante instrumento para extender la cultura, y con ella la democracia, a todos los lugares de América mediante la realización de exposiciones itinerantes.

La modernización de las instituciones anunciaba, además, la consagración de una vanguardia plenamente americana, estimulada por la llegada a Manhattan de un creciente número de artistas europeos, en muchos casos dadaístas y surrealistas ${ }^{13}$. El aluvión de vanguardistas europeos, sin embargo, era consecuencia de una situación política internacional cada vez más sombría: el $1^{\circ}$ de abril de 1939 la Guerra Civil Española, que había provocado una importante reacción en los sectores progresistas de la intelectualidad americana, acaba con la derrota de la República, confirmando la amenaza del auge de los fascismos en Europa; el 23 de agosto Hitler y Stalin firman un pacto de no-agresión; el $1^{\circ}$ de septiembre Alemania invade Polonia, y, dos días más tarde, Francia e Inglaterra declaran la guerra a Alemania; el 17 de septiembre tropas rusas invaden Polonia. Para los 400 intelectuales americanos que habían defendido a la Unión Soviética en una carta publicada en la revista Nation el 10 de agosto, la situación se había vuelto realmente complicada.

12 Roosevelt, Franklin D. Discurso radiado reproducido en Herald Tribune, New York, 11-V-1939.

13 SAWIN - ALIX, 2000. 
Este es, muy sumariamente descrito, el panorama sobre el que debe situarse el impacto inicial de Guernica en la cultura artística neoyorquina. El $1^{\circ}$ de mayo de 1939, sólo un mes después del fin de la Guerra Civil Española y justamente dos años después de que Picasso empezara a trabajar en Guernica, llegó este cuadro al puerto de Nueva York. El viaje había sido organizado por el American Artists' Congress, con el que Picasso tenía contactos, en colaboración con el Comité de Ayuda a los Refugiados Españoles. A esta organización se destinarían los fondos recogidos en la exposición que se celebraría durante tres semanas en la mencionada Valentine Gallery. Inaugurada el 5 de mayo, la exposición fue un verdadero acontecimiento. A pesar de su coincidencia con la apertura del nuevo edificio del Museo de Arte Moderno, contó con la asistencia de un buen número de personalidades de la cultura y la política americana, así como con la de Juan Negrín, el último presidente de gobierno republicano que había llegado a Nueva York en el mismo barco que las obras de arte expuestas. Durante las tres semanas que estuvo abierta, y previo pago de cinco dólares, acudieron dos mil visitantes. Stuart Davis, que estuvo en el Comité que organizó la muestra, y otros artistas como Willem de Kooning y su futura esposa, Elaine Fried, así como Dorothea Tanning y Jackson Pollock, la visitaron y han dejado constancia de la profunda impresión que les produjo bien a través de sus palabras, bien en dibujos y obras posteriores. También asistió Arshile Gorky, que pronunció un emocionado discurso en uno de los simposios celebrados esos días sobre la pintura, según recordó después Tanning ${ }^{14}$. En palabras de Dore Ashton,

Indudablemente, Guernica atrajo, tanto por parte de la prensa como por parte del público en general, el mayor número de comentarios que ninguna otra obra de arte moderno haya conseguido en América. Y lo que es más importante, conmovió profundamente a los artistas ${ }^{15}$.

Después de la clausura de la Exposición Universal de París, Guernica viajó a diversas ciudades de Europa ${ }^{16}$ para recaudar fondos de ayuda a la causa republicana, pero se presentaba ahora por primera vez junto a las sesenta y dos obras relacionadas con él, lo que permitió a los artistas neoyorquinos comprender mejor el proceso pictórico y emocional seguido por el propio Picasso en su elaboración. Tanto por el especial momento en que llegaba, como por la heroica reputación alcanzada en la gira europea previa, Guernica apareció en Nueva York como una poderosa imagen capaz de concentrar el significado más profundo de la guerra. De cualquier guerra, de todas las guerras, pues sólo el título aludía a un lugar concreto. De este modo, la

14 VAn Hensbergen, 2004, p. 110. Herschel B. Chipp, por su parte, menciona "dos simposios [organizados por el Congreso de Artistas Americanos], uno de ellos ante el cuadro y otro en el Museum of Modern Art". CHIPP, 1981, p. 118.

15 Ashton, 1979, p. 102.

16 Entre enero y abril de 1938 Guernica se exhibió en Oslo, Copenhague, Estocolmo y Gotemburgo. A finales de septiembre el cuadro viajó a Inglaterra y entre los últimos meses de 1938 y enero de 1939 se expuso en Londres, Leeds, Liverpool y Manchester. En particular, la exposición de la Whitechapel Art Gallery de Londres tuvo un gran éxito de público, y contribuyó en gran medida a sensibilizar a la opinión pública británica sobre la situación española. 
presencia de la obra en Nueva York venía a apoyar las posiciones de los artistas que, en el debate sobre las posibilidades de la nueva pintura, defendían a toda costa la necesidad de expresar significados trascendentes incluso en el caso de obras abstractas, rompiendo así el malentendido que identificaba en exclusiva al arte políticamente comprometido con los lenguajes realistas que se apoderaron de buena parte de la escena americana durante los años treinta, un malentendido que impedía resolver el conflicto entre una pintura socialmente significante y la gran tradición moderna de la experimentación formal que desembocaba en la abstracción. Picasso era reverenciado por los artistas más avanzados de Nueva York desde 1911, cuando su obra comenzó a exponerse en la ciudad gracias a las iniciativas de Alfred Stiegliz, asesorado por el pintor Max Weber -no por casualidad, otro de los miembros del comité de preparación de esta muestra-. Su constante prestigio, que en ocasiones llegó a convertirse en una especie de aplastante losa para los jóvenes artistas en busca de originalidad, se vio revitalizado gracias a su respuesta al acuciante dilema al que debían enfrentarse los artistas del momento. Un dilema en el que, de hecho, ya había terciado el artista español enviando, en diciembre de 1936 y en su recién adquirida calidad de director del Museo del Prado, el siguiente mensaje que se leyó en una de las reuniones del American Artists' Congress:

En este momento es mi deseo recordaros que siempre he creído, y todavía creo, que los artistas que viven y trabajan con valores espirituales, ni pueden ni deben permanecer indiferentes a un conflicto en el que los más altos valores de la humanidad y la civilización están en riesgo ${ }^{17}$.

A pesar de la postura oficial de neutralidad mantenida por el presidente Roosevelt, que parecía minimizar las dimensiones de la guerra española, la causa republicana había sido abrazada por amplios sectores de la intelectualidad americana ${ }^{18}$, que veían en la Guerra Civil un conflicto moral de alcance internacional, pues enfrentaba a las fuerzas del fascismo con las de la libertad. Los recuentos de testigos ilustres como André Malraux, o de otros anónimos como los miembros de la Brigada Lincoln, así como otras múltiples referencias tanto a la Guerra Civil Española como a la Guerra Mundial que se acercaba, estaban muy presentes en el ambiente cultural americano, muy sensibilizado hacia los temas políticos y sociales después de los duros años treinta.

Estas cuestiones aludían, en definitiva, al problema del artista como individuo en relación con la acción colectiva, un problema central para los atormentados artistas neoyorquinos de los años treinta, atrapados entre el compromiso con la modernidad estética y el compromiso con los problemas sociales y políticos de su tiempo. Dos compromisos que, finalmente, Picasso había hecho plenamente compatibles al fundirlos en uno sólo: el compromiso consigo mismo. Siendo fiel a sus propias convic-

17 Ashton, 1979, p. 102.

18 Con el fin de ayudar a la causa republicana se creó el Spanish Refugee Relief Campaign que, paradójicamente, contó con el apoyo del Secretario de Interior del gobierno de Roosevelt, pero también con el de Lillian Hellman, Thomas Mann, Lewis Mumford, Alfred Einstein, Ernest Hemingway, Malcolm Cowley o Dorothy Parker, entre muchos otros. MaCDonaLD, 1987. 
ciones, tanto artísticas como políticas, Picasso había señalado el camino a los artistas de la Escuela de Nueva York: ningún credo -estético o político- debía ser asumido si significaba renuncias o imposiciones. La máxima fidelidad a nuestro tiempo, la manera más inequívoca de ser moderno y comprometido, parecía decir Picasso, consiste precisamente en la fidelidad a uno mismo. La máxima expresión de solidaridad hacia su propia época era la que procedía del interior del artista. El énfasis en el artista como individuo libre resultaba especialmente adecuado en un ambiente muy sensible a las teorías del existencialismo y al hincapié en la subjetividad propio del surrealismo. Ofreciendo una imagen de hondas connotaciones míticas y simbólicas que permitían lecturas universales, Picasso mostraba una vía de unión entre lo individual y lo colectivo: Guernica procedía de lo más profundo del mundo interior del artista, pero al mismo tiempo trascendía el ámbito de lo personal apelando a la consciencia colectiva.

La exposición de la Valentine Gallery cerró a finales de mayo de 1939. En el mes de agosto Guernica se expuso en la Stendhal Gallery de Los Ángeles. En septiembre de 1939, cuando se encontraba expuesto en el Museum of Art de San Francisco, se produjo el estallido de la Segunda Guerra Mundial. Algo más tarde, a comienzos de octubre, se expuso en la Wrigley Tower de Chicago, bajo los auspicios de Arts Club. A lo largo de esta breve gira americana, Guernica había provocado un intenso debate crítico, fundamentalmente centrado en la cuestión de la relación arte-política, en buena medida espoleada por su coincidencia con el inicio de la Segunda Guerra Mundial, que ampliaba definitivamente a escala internacional el conflicto entre fascismo y libertad denunciado en el cuadro.

Guernica volvió a presentarse al público neoyorquino el 15 de noviembre de 1939, cuando se inauguró la exposición "Picasso. Forty Years of his Art" en el flamante edificio de Museum of Modern Art en la calle 51. El cuadro asumió entonces la categoría de obra maestra de la pintura moderna, mostrado en el contexto de la evolución artística de Picasso, el proteico artista capaz de resumir por sí mismo la compleja y diversa aventura de la modernidad. Si hasta entonces se entendía fundamentalmente en el marco de la Guerra Civil Española, ampliándose al de la Segunda Guerra Mundial y, finalmente, al de la guerra moderna, a partir de ahora debía insertarse en otro marco: el de la modernidad artística. De la historia de la Guerra Civil Española pasaba a la historia del arte moderno universal.

Alfred H. Barr, el mítico primer director del Museo de Arte Moderno de Nueva York, había dedicado importantes esfuerzos a conseguir una buena representación de la obra de Picasso en las colecciones del museo, coronándole como figura primordial de las dos grandes corrientes que, en su influyente visión, conformaban la evolución del arte moderno: la analítica y la emocional. Barr propuso una genealogía de estas líneas en sendas exposiciones celebradas en 1936: Cubism and Abstract Art y Dada, Surrealism and their Heritage, y en ambas otorgó a Picasso un papel protagonista. En 1939, y después de ocho años de preparación, el Museo estaba por fin listo para inaugurar la mayor exposición sobre el artista español. Para ella reunió más de 350 obras de todas las épocas y técnicas, de las que el propio pintor había prestado casi un centenar. Y entre ellas brilló con luz propia Guernica, que Barr ya había intentado exponer en su museo precisamente en mayo, para la apertura del nuevo edificio del museo. 
Dado el prestigio y la autoridad del museo organizador, y a pesar de la adversidad que suponía el momento en que se presentaba -ya en plena guerra mundial-, esta exposición marcó la pauta que aún hoy sigue rigiendo la fortuna crítica de la figura de Picasso, y contribuyó decisivamente a crear su mito como la personalidad artística más relevante del siglo XX. Alfred H. Barr realzó las líneas de cohesión existentes a lo largo de la trayectoria picassiana, y supo acercar la obra del español a las preocupaciones artísticas que entonces se registraban en el ambiente neoyorquino. Corroboraba así la imagen de Picasso como un clásico, es decir, como autor de una obra que, sitúandose más allá del tiempo, resulta siempre tan vigente como oportuna. Resaltando la importancia de Guernica, e igualando este lienzo a Les Demoiselles d'Avignon, al convertir a ambas pinturas en puntos focales de la muestra, se transmitía un mensaje de cohesión y actualidad en la obra del pintor español que subrayaba tanto la importancia histórica como la relevancia actual de ambas piezas. Sensible a la preponderancia del surrealismo en el ambiente vanguardista neoyorquino, Barr las presentó como resultado de un intenso proceso creativo en el que cobraba gran peso la visión interior. Para ello expuso dibujos preparatorios o, en todo caso, relacionados con cada una de las dos obras, lo que permitía a los espectadores reconstruir el camino recorrido por Picasso desde lo narrativo -una escena de burdel en el primer caso; una escena de propaganda aplicable a un contexto histórico concreto, en el segundo- a lo icónico, de lo individual a lo universal, explorando los conceptos de arquetipo, símbolo o mito en los que estaban interesados los jóvenes artistas neoyorquinos. Con este punto de vista, tanto Les Demoiselles d'Avignon como Guernica se presentaban como parte de procesos creativos dinámicos y complejos, en los que desempeñaba un papel fundamental la experimentación y la propia experiencia personal, aspectos clave para el expresionismo abstracto.

Michael Fitzgerald ha revisado el impacto que aquella muestra tuvo sobre los artistas que formaban parte de la escena neoyorquina del momento, deteniéndose en una jovencísima Louise Bourgeois, pero también en artistas como Stuart Davis, Arshile Gorky, Willem de Kooning o, especialmente, Pollock ${ }^{19}$. Para este último, las sucesivas exposiciones de Valentine Gallery y la del Museo de Arte Moderno supusieron la primera oportunidad importante de contemplar y apreciar la obra de Picasso en toda su complejidad. A juzgar por sus obras de esos años, como Birth, ca. 1941 (Tate Gallery, London); Masqued Image, ca. 1938-1941 (Modern Art Museum of Fort Worth, Texas) o Untitled, Orange Head, ca. 1938-1941 (Private Collection), Pollock se sintió especialmente conmovido por la obra más reciente del artista español que por su violencia formal parecía traslucir un atormentado mundo interior, y que por su aliento épico y gran formato respondía a sus propias inquietudes y aspiraciones personales. Quizá intuía, por la contemplación de todo el conjunto de obras relacionadas con Picasso, el trance creativo en el que debió sumirse Picasso en mayo de 1937, que parecía adelantar los suyos propios. Motherwell, por su parte, no llegó a contemplar entonces el lienzo del pintor español, pues en 1939 no se encontraba aún en Nueva York. La posterior presencia de Guernica en el Museo de Arte Moderno, sin embargo, permitiría a este artista familiarizarse con el cuadro, cuya

19 FitzGerald, 2006, pp. 169 y ss. 
forma y significado llegarían a obsesionarle durante toda su trayectoria posterior, como muestra su larga y célebre serie de pinturas y grabados titulada "Elegies to the Spanish Republic" 20 . Dore Ashton, gran conocedora tanto de la obra de Motherwell como de la de Picasso y pionera en el estudio de las cuestiones morales, intelectuales y sociales que subyacen en la obra de los expresionistas abstractos, ha señalado, de hecho, a Guernica como un antecedente directo de esta serie:

Las amplias implicaciones de su ensayo de indignación moral [se refiere a Picasso y a Guernica] no pasaron desapercibidas para los artistas americanos, que estaban obsesionados por la Guerra Civil Española. Al menos uno de ellos -Robert Motherwell-, continuaría enfrentándose a los problemas implícitos en el gesto titánico de Picasso ${ }^{21}$.

De una manera u otra, el grito de Guernica resuena en buena parte de la obra producida por la llamada Escuela de Nueva York. Más allá de cuestiones formales obvias, como la dramática restricción cromática al blanco, negro y gris ${ }^{22}$, la gestualidad de la pincelada o el uso del gran formato, lo que el mural picassiano planteaba era una cuestión de vital importancia: una reflexión sobre el papel social del artista en un contexto marcado por la guerra y la destrucción, defendiendo la compatibilidad del compromiso político con la experimentación formal, y sustituyendo la sumisión de la militancia por la libertad de la introspección.

Durante la Segunda Guerra Mundial y en los años inmediatamente posteriores, muchos de los artistas de la emergente Escuela de Nueva York se identificaron con el "titánico gesto" de Picasso a través del expresionismo abstracto, la principal propuesta artística del momento. Como la mayoría de los americanos, ellos también volvieron su mirada hacia un arte y un pensamiento capaz de presentar la historia "no como una progresión hacia el ideal tecnológico, sino como un drama más complejo [en el que se entremezclan] logros y fracasos humanos"23. Un drama que, en 1939 y ante los atónitos ojos de los artistas neoyorquinos, se manifestaba clamorosamente en Guernica.

\section{1947. GUERNICA Y EL EXPRESIONISMO ABSTRACTO}

El 25 de noviembre de 1947, ocho años después de "Picasso Forty Years of his art", el Museo de Arte Moderno celebró un simposio sobre Guernica, de nuevo bajo la dirección de Alfred H. Barr. De este modo, el museo singularizaba este cuadro por encima de cualquier otra pieza entre las numerosísimas obras que llegaron a reunirse en aquella muestra, y convocaba a un conjunto de expertos para debatir sobre su

${ }^{20}$ La relación entre el tema de la Guerra civil española y la obra de Motherwell ha sido estudiado en Goula, 2006.

21 Ashton, 1979, p. 103.

22 Este rasgo cromático se convirtió, de hecho, en un elemento tan distintivo de la nueva pintura americana que el galerista neoyorquino Samuel Kootz decidió realizar en 1950 una exposición con obras en blanco y negro en la que reunió trabajos de Picasso y Klee junto a otros de artistas americanos como Pollock, de Kooning, Gottlieb y Motherwell.

23 POLCARI, 1991, p. 21. 
significación en el décimo aniversario de su creación. Esta iniciativa, que confirmaba el status académico de obra maestra de Guernica, revelaría al mismo tiempo hasta qué punto seguía generando controversia y resultando plenamente actual. En realidad, más que un cambio en el significado del cuadro, lo que aquel simposio certificó fue la existencia de múltiples niveles de lectura propiciados por la tensión entre forma y contenido a la que aludíamos al principio de este artículo.

Habían pasado dos años del final de la Segunda Guerra Mundial, cuyo inicio coincidió con la primera gira americana de Guernica. Pero el ciclo histórico aún no se había cerrado del todo. Con su decisiva intervención en el conflicto, Estados Unidos se había consagrado en el panorama político mundial como gran potencia internacional. Sin embargo, la destrucción y muerte a que había dado lugar la guerra, las noticias sobre los campos de exterminio, y el establecimiento de dos mundos separados en occidente con el inicio de la Guerra Fría, entre otros factores, habían provocado una profunda crisis moral que influyó muy poderosamente en la cultura de la primera postguerra, tanto en Europa como en Estados Unidos. Ese es el contexto en que se produce, entre 1939 y 1947 el ya citado Triunfo de la pintura america$n a^{24}$, en referencia al papel protagónico que, en el ámbito internacional, alcanza la obra de los artistas del expresionismo abstracto. Algo que Serge Guilbaut ha interpretado en clave socio-política como un traspaso de la capitalidad artística de París a Nueva York ${ }^{25}$.

En efecto, 1947 es un momento clave para el expresionismo abstracto americano. Es el año de los primeros lienzos realizados por Jackson Pollock con la técnica de dripping26; el año en que Rothko empezó a adentrarse en el terreno de los campos de color plenamente abstractos, abandonando sus referencias figurativas, y el año en que Williem de Kooning comenzó a pintar las abstracciones en blanco y negro que algunos críticos consideran sus mejores obras. Es también el año en que Peggy Guggenheim cerró su galería Art of This Century, dando por culminada su misión a favor del arte moderno en el ambiente neoyorquino. Otras galerías, como Betty Parsons o Samuel Kootz celebraban exposiciones individuales de jóvenes artistas de la Escuela de Nueva York. Esta última galería, no por casualidad, dedicaba su primera exposición de 1947 al Picasso posterior a la guerra. Joan Miró, también muy admirado por los jóvenes expresionistas abstractos neoyorquinos, llega en febrero a Estados Unidos. En primavera, el mismo Museo de Arte Moderno inaugura la exposición "Large-Scale Modern Paintings", en la que participa Pollock. Para Phillip Guston y otros artistas que vivían fuera de Manhattan,

[...] las noticias que llegaban de Nueva York en 1947 eran alentadoras. Los críticos empezaban a fijarse en (aquel) pequeño grupo de artistas [...] como una auténtica vanguardia, y había nuevas galerías dedicadas al arte contemporáneo. Un crítico tan eminente como Clement Greenberg percibía un giro en los intereses de los artistas, que se

24 SANDLER, 1970.

25 Guilbaut, 1990, p. 97 y ss.

26 Aunque no suele señalarse como antecedente del dripping de Pollock, Guernica mostraba ya texturas de goteo en algunos pasajes del cuadro. 
alejaban de los principios cubistas hacia el contenido simbólico y metafórico. Aunque Greenberg no lo aprobaba, reconocía que este simbolismo servía para estimular una pintura seria y ambiciosa, permitiendo a los artistas apartar sus diferencias de ideología 27.

Probablemente uno de los mejores registros de las preocupaciones estéticas y morales del ambiente artístico del momento fue la mítica revista Possibilities, cuyo único número, editado por el pintor Robert Motherwell y el crítico Harold Rosenberg, se publicó aquel mismo otoño de 1947 y pronto alcanzó una gran difusión. En ella, con un tono muy marcado por el existencialismo y las teorías jungianas del inconsciente colectivo, el pintor Wlliam Baziotes hablaba de sus obras como reflejos de su identidad: "Son mis espejos. Me dicen cómo soy en ese momento"28. En la misma revista se publicaba un célebre texto de Pollock en el que el artista describía su forma de trabajo como un proceso experimental y complejo, refiriéndose a su pintura como un lugar o como un estado de ánimo, y a la obra terminada como el resultado de ese proceso en el que el artista se deja llevar:

Cuando estoy en mi pintura, no soy consciente de lo que estoy haciendo. Sólo después de una especie de período de "acercamiento" me doy cuenta de lo que he estado haciendo. No tengo miedo de hacer cambios, destruir la imagen, etc., porque la pintura tiene vida propia. Intento dejar que aflore. Sólo cuando pierdo contacto con la pintura el resultado es malo. Si no, es pura armonía, un fácil intercambio, y la pintura sale bien ${ }^{29}$.

Picasso había hablado del cuadro como una suma de destrucciones ${ }^{30} \mathrm{y}$, en el caso concreto de Guernica, los expresionistas abstractos probablemente percibían un proceso afín a ese intercambio con la pintura descrito por Pollock, dejando que aflorase su propia vida. De hecho, podían asomarse a ese proceso no sólo a través de las más de sesenta obras que rodearon a la creación del mural como en una impresionante meditación en voz alta, sino también a través de la serie de fotografías de Dora Maar. Al mismo tiempo, probablemente percibían en el cuadro picassiano todo lo que tenía de gesto público, de mediador entre el mundo interior del artista y su época. Pero la comunicación que se producía mediante Guernica no venía condicionada por mensajes concretos; al contrario, apelaba a la receptividad de cada espectador, que en cada caso transformaría el significado de la pieza.

En una entrevista realizada en noviembre de 1944, y ante la insistencia del entrevistador, Jerôme Seckler, un marchante y pintor que se encontraba entre los miembros de las tropas americanas que liberaron París, declaraba: "No, el toro no es el fascismo, sino brutalidad y oscuridad". Algo más tarde, decía:

Mi obra no es simbólica [...] Sólo el mural Guernica es simbólico. Pero en el caso de este mural, eso es alegórico. Por esta razón he utilizado el caballo, el toro, etc. ${ }^{31}$

27 Ashton, 1990, p. 78.

28 BAZiotes 1947, citado en Ashton, 1979, p. 182.

29 POLLOCK, 1947, p. 79.

30 Zervos, 1935, p. 173.

31 Cita en CHIPP, 1968, pp. 487-488. 
Picasso reconocía la enorme carga emocional del cuadro, que había explotado de forma plenamente consciente y que, en todo caso, era fundamentalmente un reflejo de sus propias emociones, de su indignación frente a la barbarie que representaba el bombardeo de la ciudad vasca de Guernica. Pero se negaba a encerrar aquella indignación en etiquetas concretas, ni políticas ni estéticas. Estas ideas y otras directamente relacionadas con ellas, que apuntaban a los debates subyacentes en el propio expresionismo abstracto y a la necesidad de responder a momentos de gran violencia con un arte violento ${ }^{32}$, protagonizaron el encuentro celebrado en el Museum of Modern Art en 1947. Además del propio Barr, que en calidad de anfitrión abrió la sesión y moderó la discusión posterior, en el encuentro participaron los siguientes ponentes: el arquitecto Josep Lluis Sert, autor junto con Luis Lacasa del Pabellón de la República Española al que se destinó originalmente Guernica; el mencionado Jerôme Seckler; el poeta Juan Larrea, que ese mismo año había publicado la primera monografía sobre el mural de Picasso, editada en Nueva York y prologada precisamente por Barr ${ }^{33}$, reproduciendo las fotos de Dora Maar sobre la realización del cuadro; así como el escultor Jacques Lipschitz y el pintor Stuart Davis.

Picasso, el gran ausente en esta convocatoria, había escrito en mayo de 1937, justamente cuando estaba inmerso en la realización de Guernica y con motivo de una exposición de carteles republicanos celebrada en Nueva York, una declaración en la que afirmaba:

La lucha de España es la lucha de la reacción contra el pueblo, contra la libertad. Toda mi vida como artista ha sido una continua lucha contra la reacción y contra la muerte del arte [...] En el panel en el que estoy trabajando ahora, y que llamaré Guernica, y en todas mis obras recientes, expreso claramente mi horror hacia la casta militar que ha hundido a España en un océano de dolor y muerte ${ }^{34}$.

Aparte de esta declaración genérica, que expresaba muy claramente su posicionamiento político, Picasso dejaba abiertas todas las incógnitas acerca de la interpretación simbólica de los elementos del cuadro. Por ello era inevitable que la lectura tuviese que ver con la mirada de cada espectador. De hecho, una parte del debate, a juzgar por las actas, se dedicó a la confrontación de las teorías de Seckler y las de Larrea acerca de los significados de los personajes y objetos del lienzo que, siendo absolutamente contrapuestas, resultaban igualmente plausibles. Pero más allá de esta cuestión, que desde la perspectiva actual resulta casi anecdótica, lo que se puso de manifiesto en aquel simposio, tan significativo por su fecha, su sede y sus ponentes -y probablemente también, aunque no tengamos constancia documental de sus identidades, por su público-, es la capacidad de Guernica, como verdadera obra maestra, de apelar y responder a las cuestiones más acuciantes de cada generación. Porque, superando el comentario de las circunstancias en las que nació la obra, e incardinándose plenamente en el momento y el lugar en que se desarrollaba el simposio, el

\footnotetext{
32 Bozal, 2005, p. 19 y ss.

33 Ver LARREA, 1947.

34 Cita en BARR, 1966, p. 202.
} 
Guernica mostró su capacidad de apelar y responder, en los propios términos del momento, a interrogantes que podrían plantearse a propósito de las obras que salían entonces de los talleres de los expresionistas abstractos: ¿pinta el artista en un estado de trance, dejándose llevar por la propia pintura?, ¿hasta qué punto es el artista consciente de lo que pinta, de su significado o de su simbología?, ¿no era cierto que esta simbología, por surgir del interior del artista pero responder a problemas colectivos, se haría clara para quien contemplase el cuadro por apelar a una consciencia colectiva, como proponían los seguidores de las teorías de Jung en Nueva York?, ¿es posible conciliar la experimentación formal con la necesidad de responder a una época trágica?

En aquel debate el poeta Juan Larrea, cuyo libro ha sido durante décadas la referencia canónica a la hora de acercarse al Guernica, se mostraba más proclive que Seckler a una interpretación trascendente del cuadro. Larrea se mostraba, por tanto, más en línea con su consideración de obra maestra, es decir, de obra de arte universal e intemporal. Después de exponer su interpretación -de carácter cercano a lo místico y muy en relación con determinados arquetipos míticos de la cultura españolade los elementos que configuran el cuadro, Larrea consiguió (a diferencia de Seckler) sortear el peligro de caer en la trampa de quedar atrapado en la especificidad de este lienzo y de sus circunstancias. Para ello realizó una serie de reflexiones de carácter teórico y general que integraban plenamente a Guernica en los debates del momento, y mostraban tanto la sensibilidad del propio poeta hacia los problemas artísticos de su época como la sagacidad de Barr al prologar su libro. Así, Larrea observó que

[...] por varias razones, la pintura se está alejando cada vez más de la realidad perceptible, explorando lo abstracto a lo largo de caminos rocosos iluminados de vez en cuando por un estado de ánimo especial, no muy diferente de lo que podemos llamar "noche mística". El objetivo de ambos procesos es llegar a una identificación con el espíritu de universalidad. No cabe duda de que la cuestión de la universalidad de la consciencia es una de las más importantes que afrontamos hoy.

Más adelante, exponía:

La pintura, como las matemáticas, tiene posibilidades ilimitadas [...] Pero lo que realmente interesa al artista, lo que realmente importa, es la máxima posibilidad del arte, la que le sitúa en un nivel psíquico superior desde el cual puede alcanzar la esencia del ser. Esta ha sido la gran aspiración de las generaciones pasadas. Desde ese punto de vista, Guernica abre nuevas perspectivas, permitiéndonos esperar que la función del artista alcanzará en el futuro una incomparable dignidad y nobleza. ¿No son los artistas quienes se esfuerzan para resolver problemas que son humanos $\mathrm{y}$, por tanto, nos conciernen a todos? [...] El arte, por tanto, es la vía a través de la cual nuestra conciencia puede penetrar en los secretos más profundos del ser humano y usar las facultades sobre las que se basa la creación de una nueva sociedad: en [...] el mundo del espíritu 35 .

Como ha señalado David Anfam, "los artistas modernos suelen relacionar sus crisis privadas con acontecimientos externos, y los expresionistas abstractos no fue-

35 LARREA, 1947, pp. 55-56. 
ron una excepción"36. Picasso tampoco lo fue. Es sabido que, en la gran catarsis pictórica de Guernica se expresaba, fundido con la angustia por la situación de todo un pueblo, de toda una cultura, el desasosiego vivido en el terreno personal durante los últimos años -no en vano, Picasso había señalado aquellos años como "los peores de su vida"37-. En la entrevista de Seckler antes citada, Picasso había manifestado que no pintaba lo que veía, sino lo que pensaba y sentía. Al mismo tiempo, es conocida su aversión al llamado "arte por el arte"; es decir, a un arte desconectado de la naturaleza y justificado solo como una evasión esteticista. El arte debía transmitir contenidos, pero esos contenidos no tenían que estar necesariamente limitados por la naturaleza observada sino que, más bien al contrario, debían obedecer a otra naturaleza: la del interior del artista. Esta es la idea que resuena en las palabras pronunciadas al otro lado del océano Atlántico por el joven Pollock cuando, increpado en 1942 por el pintor de origen alemán, Hans Hofmann, por no trabajar a partir de la naturaleza, exclamó: "Yo soy la naturaleza"38.

Pollock había sufrido en 1937 una profunda crisis personal que acabó en su hospitalización por alcoholismo, y sus obras de aquellos años mostraban todo su tumulto interior mediante formas que recordaban, en su atormentada expresividad, a las realizadas por Picasso en esa misma década. Pero al mismo tiempo, en el transcurso del tratamiento psiquiátrico seguido ese año y los siguientes, Pollock entendió que su pintura daba una dimensión trascendente, social, a su desasosiego:

Pollock acabó por convencerse de que la fuente de su arte estaba en su inconsciente, una conclusión muy sincera a la que difícilmente habría llegado sin conocer las nuevas prioridades de la vanguardia neoyorquina en la terrible encrucijada de la historia occidental $^{39}$.

Stuart Davis que, como se recordará, había participado también en la organización del viaje de Guernica a Estados Unidos, fue quizá el ponente que expresó una mayor distancia respecto a los valores artísticos del cuadro, al que sin embargo mostraba todo su respeto. Por generación, Davis pertenecía más a la retaguardia histórica de la primera modernidad americana que a la vanguardia del expresionismo abstracto de la postguerra. Sin embargo, como pintor al fin y al cabo, en una de sus intervenciones se refirió certeramente a la preocupación que había atormentado a los artistas americanos durante la primera parte del siglo XX: la relación del artista, como individuo, con la colectividad, para concluir que "pintar es, en sí mismo, un acto social". Esa era, en definitiva, la lección de Guernica. Esa era, por encima de las cuestiones formales, su principal aportación.

Quizá por eso Picasso era una excepción para los jóvenes artistas neoyorquinos que, después de años de preponderancia de los distintos tipos de realismo que respondían a los imperativos ideológicos tanto del nuevo regionalismo como de la pintura social, habían llegado a aborrecer la pintura figurativa, considerándola propia de

\footnotetext{
36 ANFAM, 1990, p. 77.

37 Calvo Serraller, 1999, pp. 18-22. Ver también Nash, 1998.

38 ANFAM, 1990, p. 56.

39 Ibidem, pp. 75-76.
} 
una época ya pasada. Aborrecer la figuración tal como se entendía tradicionalmente, sin embargo, no significaba renunciar a los contenidos. Picasso lo había demostrado.

Considerada ya incuestionablemente una obra maestra del arte moderno internacional, conservada y estudiada hasta 1981 en el museo que había creado el relato canónico para entender no sólo a Picasso, sino a todo el arte moderno, Guernica se convirtió en un faro incuestionable al que acudían tanto quienes deseaban aprender de su libertad formal como aquellos que veían en el cuadro un símbolo político. Entre 1937 y 1947, los años del surgimiento de la llamada Escuela de Nueva York, parece producirse una metamorfosis -palabra de connotaciones surrealistas especialmente presente en la literatura artística de aquella época- en la apreciación crítica de Guernica. Con el paso del tiempo descubrimos que, en realidad, todos los significados estaban, desde siempre, contenidos en aquel lienzo. Con la polisemia propia de cualquier obra maestra, Guernica ha sabido dar respuesta a cuantos la han mirado, como si desde el principio tuviese en cuenta las múltiples perspectivas desde las que sería observado. Como señalaba Brown a propósito de Las Meninas, la grandeza de Guernica consiste precisamente en escapar de toda visión unívoca y, por tanto, reductora. Como Las Meninas, Guernica ha sido y sigue siendo reinterpretado por cada generación, mostrando una inmensa capacidad de respuesta que le ha permitido enriquecer el debate artístico, social y político hasta convertirse en todo un emblema del siglo XX.

\section{CODA. VUELTA A LAS MENINAS}

Significativamente, el congreso sobre Guernica celebrado en 1947 en el Museo de Arte Moderno se cerró con una alusión al papel de Picasso como "profeta". Diez años más tarde, consciente de su lugar en la historia del arte y de la importancia que Guernica, convertida en una obra maestra de la modernidad por asumir la defensa de su valor máximo, la libertad, Picasso sintió la necesidad de medir sus fuerzas con la otra gran obra maestra de la pintura española que había capturado la imaginación de los artistas americanos unas décadas antes, dedicando, en 1957, toda una suite de más de medio centenar de obras a Las Meninas. Con toda la modestia y toda la soberbia que ello significaba, y siguiendo ahora el camino trazado por otros artistas antes que él, Picasso decide emular a un clásico cuando él mismo era ya otro clásico ${ }^{40}$. Como en el caso de Las Meninas, el paso del tiempo no ha hecho más que confirmar la fuerza de Guernica. Si la primera sirvió a los artistas americanos del cambio de siglo como ejemplo de un arte profundamente personal, diferente al marcado por la visión académica, el segundo confirmó a los artistas de la Escuela de Nueva York la posibilidad de ser plenamente modernos sin renunciar a los contenidos, y la inseparabilidad del compromiso artístico y el vital.

40 Ver BRown, 1978. 


\section{REFERENCIAS BIBLIOGRÁFICAS}

AA.VV.

1981 Guernica-Legado Picasso. Madrid. Ministerio de Cultura.

2006 Picasso. Tradición y Vanguardia. Madrid. Museo Nacional del Prado Museo Nacional Reina Sofía.

ANFAM, David

1990 Abstract Expressionism. London. Thames and Hudson.

ASHTON, Dore

1979 The New York School. A Cultural Reckoning. New York. Penguin.

1990 A Critical Study of Philip Guston. Berkeley. University of California Press.

BARR, Alfred H., Jr.

1966 Picasso. Fifty Years of His Art. Nueva York. Museum of Modern Art. Reprint edition.

BAZIOTES, William

1947 "I Cannot Evolve Any Concrete Theory". Possibilities. New York. n 1, p. 2.

Boone, M. Elizabeth

2003 "Why Drag in Velázquez? Realism, Aestheticism and the Ninetheenth Century American Response to Las Meninas". En STRATTON-PrUitT, Suzanne (ed.). Velázquez. Las Meninas. Cambridge - New York. Cambridge University Press, pp. 80-123.

Bozal, Valeriano

2005 El tiempo del estupor. Madrid. Siruela.

BROWN, Jonathan

1978 Images and Ideas in Seventeenth Century Spanish Painting. Princeton. Princeton University Press.

Calvo Serraller, Francisco

1999 El Guernica de Picasso. Madrid. TF.

Calvo Serraller, Francisco

2006 "Picasso frente a la historia", en AA.VV., pp. 27-73.

CHIPP, Herschel B.

1968 Theories of Modern Art. A Source Book by Artists and Critics. Berkeley, Los Angeles - London. University of California Press.

1981 "Génesis y primeros avatares del Guernica". En AA.VV., pp. 80-148.

FitZGERALD, Michael:

2006 Picasso and American Art. New Haven - London. Whitney Museum of American Art - Yale University Press.

Guilbaut, Serge

1990 De cómo Nueva York robó a París la idea del arte moderno. Madrid. Mondadori. 
GoulA, Elisabet

2006 L'Impacte de la guerra civil española en l'Escola de Nova York: una lectura politica de les Elegies to the Spanish Republic de Robert Motherwell. Trabajo de investigación inédito. Barcelona. Universidad Pompeu Fabra.

GreELEY, Robin, Adele

2006 Surrealism and the Spanish Civil Warr. New Haven - London. Yale University Press.

LARREA, Juan

1947 Guernica. Prólogo de Alfred H. Barr. Nueva York. Valentine Gallery. [Reeditado en Madrid, Cuadernos para el Diálogo, 1977, con prólogo de Santiago Amón].

MACDONALD, Nancy

1987 Homage to the Spanish Exiles. Voices of the Spanish Civil War. New York. Insight Books.

MARIAS, Fernando (ed.)

1995 Otras Meninas. Madrid. Siruela.

NASH, Steven A. (ed.)

1998 Picasso and the War Years. 1937-1945. San Francisco. Thames and Hudson - Fine Arts Museum.

POLCARI, Steve

1991 Abstract Expressionism and the Modern Experience. Cambridge. Cambridge University Press.

POLLOCK, Jackson

1947 "My painting". Possibilities. New York. n 1, p. 79.

RAMIREZ, Juan Antonio

1994 Picasso. El mirón y la duplicidad. Madrid. Alianza.

SANDLER, Irving

1970 The Triumph of American Painting. A History of Abstract Expressionism. New York. Icon Editions - Harper and Row Publishers.

SAwIN, Martica - Alix, Josefina

2000 Surrealistas en el exilio. Los inicios de la Escuela de Nueva York. Madrid. Museo Nacional Centro de Arte Reina Sofía.

SEMPRÚN, Jorge

2006 "Ahora empieza la pintura moderna". En AA. VV., pp. 21-26.

Stratton-Pruitt, Suzanne L. (ed.),

2003 Velázquez. Las Meninas. Cambridge University Press.

TinTEROW, Gary - LACAMBRE, Geneviève (eds.)

2003 Manet / Velázquez. The French Taste for Spanish Painting. New Haven - London - New York. Metropolitan Museum of Art - Yale University Press.

Museum OF MOdern ART

1947 Symposium on Guernica. Actas del simposio celebrado en el Museo de Arte Moderno, noviembre de 1947, Nueva York. 
VAn Hensbergen, Vegis Gijs

2004 Guernica. Autobiography of a Twentieth Century Icon. Londres. Bloomsbury Publishing.

WEINBERG, Barbara H.

2003 “American Artists' taste for Spanish Painting". En Tinterow LACAMBRE (eds.), pp. 259-307.

ZERvos, Christian

1935 “Conversation avec Picasso". Cahiers d'Art. París. nº 7-10, p. 178. 